\title{
Vocabulary structure affects word recognition: Evidence from German listeners
}

\author{
Jenny $Y^{1,2}$, Robert Mailhammer ${ }^{1}$, Anne Cutler ${ }^{1,2}$ \\ ${ }^{1}$ The MARCS Institute, Western Sydney University, Australia \\ ${ }^{2}$ ARC Centre of Excellence for the Dynamics of Language, Australia \\ jenny $\cdot$ yu@westernsydney . edu . au
}

\begin{abstract}
Lexical stress is realised similarly in English, German, and Dutch. On a suprasegmental level, stressed syllables tend to be longer and more acoustically salient than unstressed syllables; segmentally, vowels in unstressed syllables are often reduced. The frequency of unreduced unstressed syllables (where only the suprasegmental cues indicate lack of stress) however, differs across the languages. The present studies test whether listener behaviour is affected by these vocabulary differences, by investigating German listeners' use of suprasegmental cues to lexical stress in German and English word recognition. In a forced-choice identification task, German listeners correctly assigned single-syllable fragments (e.g., Kon-) to one of two words differing in stress (KONto, konZEPT). Thus, German listeners can exploit suprasegmental information for identifying words. German listeners also performed above chance in a similar task in English (with, e.g., DIver, diVERT), i.e., their sensitivity to these cues also transferred to a nonnative language. An English listener group, in contrast, failed in the English fragment task. These findings mirror vocabulary patterns: German has more words with unreduced unstressed syllables than English does.
\end{abstract}

Index Terms: lexical stress, word recognition

\section{Introduction}

In variable lexical stress languages, such as English, Dutch, and German, stressed and unstressed syllables differ acoustically: stressed syllables tend to be longer, louder, and show greater pitch movement than unstressed syllables (though see [1] for a review). Vowel quality also differs; vowels in unstressed syllables are often reduced, and stressed syllables cannot contain reduced vowels (e.g., schwa) [2]. These differences may help listeners distinguish more rapidly between candidate words during speech recognition.

Results of word recognition studies, however, suggest that this potential help is used differently ([3] has an overview). In English, listeners prove to attend primarily to segmental stress cues (i.e. whether the vowel is reduced or full) and largely disregard suprasegmental cues (F0, amplitude, duration) in lexical activation [4-7]. By contrast, studies in Dutch indicate suprasegmental stress information facilitates word recognition. Studies using gating and cross-modal priming have found that listeners identify the stress pattern of a heard fragment (e.g. OCto; NB: capitals signify stressed syllables) and match it to a word (octopus, not October) before further disambiguating cues are heard [8-11]. Further, Dutch listeners can exploit suprasegmental cues to accurately assign single-syllable fragments (e.g., hum-) to one of two words differing in stress (HUman, huMANE) in English, even outperforming native English speakers who failed at identifying non-initially stressed cases such as hum- from huMANE [4].

English and Dutch vocabulary structure has been invoked to explain this asymmetry. In English, syllables are either stressed with a full vowel or have a reduced vowel and no stress; unstressed syllables with a full vowel are rare [2]. Thus, English words contrasting in stress usually differ segmentally, making suprasegmental information largely redundant. Dutch has less vowel reduction and many more unstressed syllables with full vowels. Words in Dutch contain on average 1.52 embedded other words if stress is ignored; stress information, however, reduces the number of embeddings (and therefore, competition) by more than half [12]. By contrast, in English, the prevalence of vowel reduction results in comparatively low levels of embedding whether stress is considered or not (0.94 vs 0.59) [13]. Attending to suprasegmental stress cues therefore aids word recognition more in Dutch than English.

Although word recognition data for German from studies directly analogous to [8-10] are not available, German may show a similar pattern to Dutch because words with unstressed syllables having full vowels are more common in German than in English giving similar embedding levels as Dutch [12, 14]. Evidence from event-related potential (ERP) studies suggest German listeners can use suprasegmental correlates to stress for word identification [15-17]. However, behavioural results from these studies have been less clear. Using a unimodal paradigm, in which participants heard prime syllables followed by target words, [17] found neural responses to stress priming. Behavioural data, however, showed no reliable facilitation when prime syllables matched target words in stress (e.g., MAN- and MANdel) compared to targets with a stress pattern that did not match $(M A N-$ and manDAT), with similar results in [15]. One explanation for these results could be due to the skew of reduced syllables to syllables with full vowels in German, which is significantly higher than in either English or Dutch (cf. the English-Dutch-German cognate sets cat-kat-Katze or soup-soep-Suppe; the German word in many such sets has an extra reduced syllable) [18]. This pattern may outweigh the availability of unstressed unreduced syllables, to which the Dutch-English difference was ascribed, and which the German lexicon also shows. If so, the vowel imbalance, to which the English pattern is attributed, might affect German listeners to the extent that they resemble English listeners.

We therefore examine the effect of these vocabulary differences on German listeners' word recognition using forced-choice identification tasks. First, German listeners heard a first syllable (e.g., kon) taken from one of two German words in matching pairs with different stress (e.g., KONto 'account' vs. KonZEPT 'concept'). German listeners' ability to attend to suprasegmental cues in a non-native language was also investigated using similar monosyllabic English fragments. If German listeners can exploit suprasegmental stress information, then listeners should correctly assign fragments to words in both languages; they may even outperform English listeners with English materials (as Dutch were found to do). However, if the higher frequency of reduced syllables strongly affects listener behaviour, then the observed pattern for German may resemble that for English. 


\section{Experiment 1}

All experiments tested the recognition accuracy for words based on an initial monosyllabic token. Words had either first syllable primary stress or second syllable primary stress. For ease of explanation, stress in this paper will only refer to primary stress though other levels of stress exist, e.g., secondary.

\subsection{Method}

\subsubsection{Participants}

Twenty-one native speakers of German $\left(\mathrm{M}_{\mathrm{age}}=27.62, \mathrm{SD}\right.$ $=8.52,16$ females) participated for either course credit or small payment. Participants were recruited in Potsdam and most grew up around Eastern Germany. There were no simultaneous bilinguals and participants had no self-reported speech, reading, or hearing issues.

\subsubsection{Stimuli}

A search of the CELEX database [19] produced 36 pairs of German words (mostly disyllabic) of the Konto-Konzept type: one member had stress on the first syllable, the other stress on the second syllable. The first syllables of each word pair differed only in stress; their segments were identical.

A further selection among these pairs was then made via a pretest in which the 72 words were presented together with 48 other German words (with varying frequency) to 11 native German speakers from the same population as above. Participants were recorded reading out each word and rated how familiar they were with the word on a 7-point scale, with 7 signaling high familiarity. 24 pairs were selected for use in the experiment based on the results of the pretest. All chosen words were known by participants and had received a mean familiarity rating of 4 or above, indicating at least moderate familiarity (mean familiarity ratings for first syllable stress words was $6.22, \mathrm{SD}=0.58$; for second syllable stress words, $6.19, \mathrm{SD}=0.47)$. To reduce response bias within word pairs, words were also matched on familiarity and frequency (mean $\log$ frequency for first stress target words was $1.07, \mathrm{SD}=0.66$; for second syllable stress words, $1.12, \mathrm{SD}=0.53$; the mean absolute difference in log frequency between members of the same pair was $0.26, \mathrm{SD}=0.26$ ). A complete list of items is given in the Appendix.

Two instances of each word were recorded by a female native speaker of German from Eastern Germany with no knowledge of the experiment's goal. Words were recorded in a randomised order, so as not to exaggerate stress patterns in word pairs. In Praat [20], each word was cut at the offset of the first syllable and extracted to serve as token stimuli: 96 fragments in all (24 pairs x 2 source words x 2 productions).

Most pairs (19 out of 24) were also phonemically identical at the start of the second syllable. This precluded variably present fragment-final co-articulatory cues and allowed us to maximize the material from each fragment and thus avoid presenting incomplete syllables.

\subsubsection{Procedure}

Participants were tested individually in a quiet room in a session lasting approximately an hour. Presentation [21] software was used to present the stimuli and record participant responses.
The experiment consisted of a forced-choice task in which participants listened to a word fragment and then judged the source of the fragment. Each trial began with the presentation of "New Trial" on screen for 500ms. Participants then heard a word fragment over headphones. Immediately following the offset of the word fragment, a word pair was presented in the middle of a screen; one word was shown towards the left side of the screen, the other on towards the right and participants were asked to select the source of the current fragment using the left and right "Shift" keys. Trials timed out after $5000 \mathrm{~ms}$. Items were pseudo-randomised (no successive occurrences of the same word pair) for each participant. The task consisted of two occurrences of each fragment (192 tokens in all); for one presentation the correct response was the left word of the pair, and for the other presentation the right word. Prior to starting experimental trials, participants were given two practice trials and a period to ask questions to ensure they were comfortable with the method.

\subsection{Results}

Following testing, it was discovered that in a contrastive position, damit from the pair damals-damit could be stressed on the first and not, as intended, only on the second syllable. This pair was consequently excluded from all analyses.

\subsubsection{Acoustic analysis of items}

To validate acoustic differences between stressed and nonstressed syllables, duration, f0, and intensity were computed for each truncated syllable. Table 1 presents the mean values averaged across the 46 ( 23 pairs $\times 2$ recordings) syllables of each stress type.

Stressed syllables were longer, louder, had higher pitch, and were more variable in F0 than syllables without stress. There were significant statistical differences between the two syllable types on all measures, with $\mathrm{p}<.001$ for all measures except intensity. The two recordings of each word also correlated positively on all measures, in nearly all cases.

Table 1: Mean values (SD in brackets) of acoustic measures for syllables with stress (Str 1, e.g., Kon- from Konto) versus syllables without (Str 2, e.g., Kon- from Konzept), with pvalue of their differences based on paired-samples t-tests.

\begin{tabular}{cccc}
\hline & Str 1 & Str 2 & $\boldsymbol{p}$ \\
\hline \multirow{2}{*}{ duration (ms) } & 240.02 & 167.42 & $<.001$ \\
& $(60.69)$ & $(52.75)$ & \\
min f0 (Hz) & 207.60 & 195.06 & $<.001$ \\
& $(43.20)$ & $(18.11)$ & \\
mean f0 (Hz) & 230.77 & 214.21 & $<.001$ \\
& $(46.95)$ & $(39.05)$ & \\
max f0 (Hz) & 271.23 & 240.73 & $<.001$ \\
mean intensity (dB) & $(102.83)$ & $(83.80)$ & \\
\hline
\end{tabular}

\subsubsection{Accuracy}

18 items were excluded from the analysis due to no response and 1 item was excluded for improbable reaction time $(<200 \mathrm{~ms})$. The final dataset for analysis consisted of 3845 items.

Binomial tests were used to compare participants' performance to chance. Participants assigned fragments from 
both first- and second-syllable stress source words significantly above chance (first: mean accuracy 76.47, $\mathrm{p}<.001$, second: mean accuracy 59.56, $\mathrm{p}<.001)$. Figure 1 displays mean proportion accuracy as a function of stress.

The effect of stress type on accuracy was analysed using binomial mixed effects regression models in $\mathrm{R}$ [22] with stress (first, second) as a fixed factor and subject and item as random intercepts [23]. Stress was also added as a random slope for both subject and item as model fit improved based on LogLikelihood [24].

There was a highly significant effect of stress, with participants assigning fragments from first-syllable stress source words more accurately than fragments from secondsyllable stress words $(\beta=0.92, \mathrm{SE}=0.31, \mathrm{z}=2.73, \mathrm{p}=.003)$.

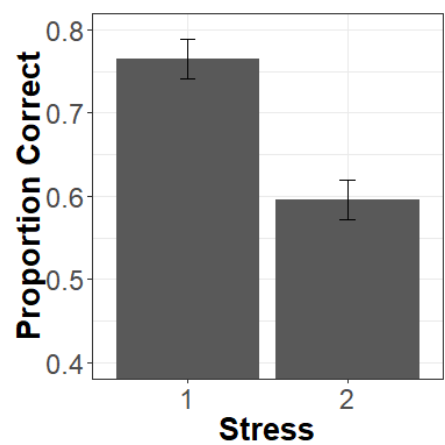

Figure 1. Mean proportion correct assignments of fragments from German words with first- and second-syllable stress.

\subsection{Discussion}

Results showed that German listeners successfully assigned monosyllabic fragments to words based on stress, with an overall performance level of $68 \%$. These results support previous work by [15-17] showing German listeners respond neurally to suprasegmental stress correlates for lexical access and extend these findings by finding robust and explicit use of this information for word recognition. These findings also indicate that German listeners can effectively use suprasegmental stress cues for lexical access similar to Dutch $[8,9]$ and Spanish [25] listeners.

In addition, results found participants were more accurate with stressed fragments compared to those without. This could reflect that more acoustically salient syllables are easier to assign than less salient ones. This may also indicate a bias to respond to words with a statistically more probable pattern (primary stress on the first syllable is the most common pattern in German). However, performance for fragments without primary stress was also above chance, indicating responses were not solely driven by stress bias.

\section{Experiment 2}

In Experiment 2, we tested whether German listeners can also use suprasegmental stress cues effectively for lexical access in a non-native language. We therefore replicated Experiment 1 but with English stimuli from [4]. The test pairs are listed in the Appendix (note: test pairs contrast in stress for Australian English; stress placement may differ in other varieties). Native Australian English listeners were tested for comparison.

\subsection{Method}

\subsubsection{Participants}

Twenty-two native speakers of German $\left(\mathrm{M}_{\mathrm{age}}=23.38\right.$ years, $\mathrm{SD}=5.01,16$ females) and 21 native speakers of Australian English $\left(\mathrm{M}_{\mathrm{age}}=24.90\right.$ years, $\mathrm{SD}=7.04,17$ females) participated for course credit or a small payment. German speakers were recruited in Potsdam and were proficient in English (mean score of $74 \%$ on the LexTALE task [26]). English speakers were recruited in Sydney. For Australian English participants, 4 grew up in a bilingual household, however all considered English their mother tongue and dominant language. All participants had normal hearing and normal or corrected-to-normal vision.

\subsubsection{Stimuli and procedure}

Stimuli were 20 English word pairs and monosyllabic fragments taken from Experiment 3 of [4] (the pair bookingbouquet was excluded due to variation in pronunciation amongst our participant group). The procedure was otherwise identical to Experiment 1.

\subsection{Results}

28 missing items were excluded from the analysis and one item was excluded for improbable reaction time. The final dataset consisted of 6850 items (3504 from German participants, 3346 from English participants).

\subsubsection{Accuracy}

Binomial tests were used to compare participants' performance to chance (see Figure 2). German listeners performed significantly above chance for both stressed syllables (mean accuracy 64.48\%, p<.001) and unstressed syllables (mean accuracy $55.37 \%, \mathrm{p}<.001$ ), indicating they were able to use the suprasegmental cues available to assist word identification. English listeners also performed significantly above chance for stressed syllables (mean accuracy $63.48 \%, \mathrm{p}<.001)$, but not for syllables without stress (mean $49.01 \%, p=0.77$ ), suggesting they were unable to use suprasegmental cues to correctly distinguish words when the fragment was not stressed.

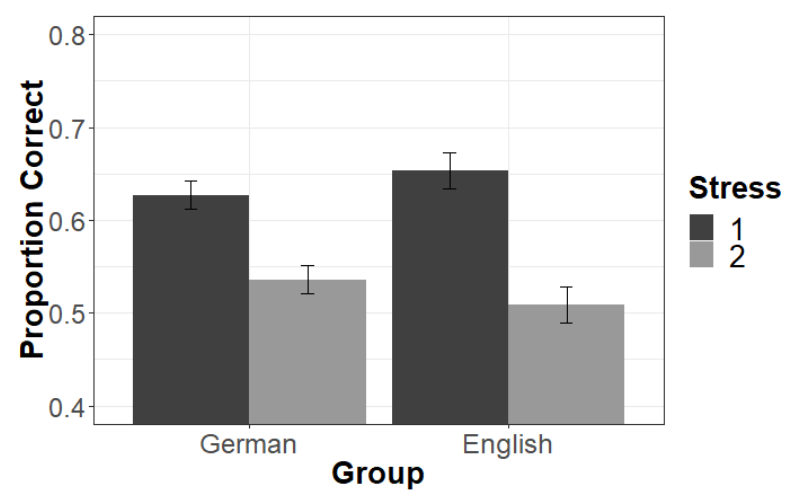

Figure 2. Mean proportion correct assignments of fragments from English words with first- and second-syllable stress by German and English listeners. 
Effects on accuracy were analysed as in Experiment 1 with stress and group (German, English) as fixed factors and subject and item as random intercepts. The final model also included stress as a random slope for subject and stress and group as random slopes for item. Planned group comparisons comparing the accuracy between German and English listeners were conducted using the emmeans function [27].

There was a main effect of stress such that participants assigned fragments from first-syllable stress words more accurately than fragments from second-syllable stress words $(\beta=0.65, \mathrm{SE}=0.12, \mathrm{z}=5.30, \mathrm{p}<.001)$. However, there was no main effect of group $(\beta=0.04, \mathrm{SE}=0.17, \mathrm{z}=0.26, \mathrm{p}=$ $0.79)$ or interaction between stress and group (Wald $\chi^{2}(1$, $\mathrm{N}=43)=2.41, \mathrm{p}=0.19$ ). Planned contrasts also found no difference in performance between German and English speakers for stressed tokens (German: 64.48\%, English: $63.48 \% ; \beta=0.04, \mathrm{SE}=0.17, \mathrm{z}=0.26, \mathrm{p}=0.80)$ and unstressed tokens (German: 55.37\%, English: $49.01 \% ; \beta=$ $0.28, \mathrm{SE}=0.16, \mathrm{z}=1.75, \mathrm{p}=0.08)$.

\subsection{Discussion}

Both German and English listeners successfully assigned monosyllabic fragments to words when fragments bore stress, but only German listeners could do this successfully with fragments not bearing primary stress; English listeners were unable to identify the correct word in the latter case.

\section{General Discussion}

Overall, German listeners were successful at using suprasegmental cues to identify words in both German and English. This suggests that German listeners can exploit suprasegmental information for word identification in their native language, and that this sensitivity to attend to these cues also transfers to a non-native language. In contrast, English listeners failed to identify source words in their native language when fragments were not stressed (e.g. di- to divert); performance was at chance level, replicating [4].

These findings are consistent with predictions from lexical statistics and support the notion that listeners' use of stress information in lexical activation is molded by their lexicon. Vocabulary analyses demonstrate that potential lexical competition is high in German and stress information decreases word activation by more than half [12] Consequently, German listeners are trained by their lexicons to attune to suprasegmental cues for significant help with inter-word competition. This also explains why non-native listeners succeed while native English listeners repeatedly fail in the same task; in English there is less incentive to attend to suprasegmental stress information as English words that contrast in stress almost always differ segmentally.

However, while German listeners succeeded in the English task, German listeners' performance was not significantly better than their English counterparts at $60 \%$ and $56 \%$ correct, respectively. This result differs from [4] who found Dutch listeners outperformed native English listeners $72 \%$ to $59 \%$ with the same materials. This may reflect that the higher frequency of reduced syllables in German affects listener behaviour in a similar way to English and may indicate Dutch listeners are even more attuned to suprasegmental cues than German listeners; however, it is difficult to compare the performance of Dutch and German groups between these two experiments. English proficiency was not matched between groups and Dutch listeners tend to be exposed to more English than German listeners [28]. Task demands also differed slightly; the present experiment was also conducted on-line while in [4] the task was off-line. Therefore, further studies matching listener groups are needed. Nevertheless, these results provide an interesting possibility for non-native listeners who are generally at a disadvantage in comparison to native listeners [29-33]. Making use of these cues, that are present even if redundant for native listeners, could perhaps counteract some of the non-native disadvantage.

Future research should also continue to examine crosslinguistic sensitivity to suprasegmental stress information and focus on non-native listening of other languages (e.g., English speakers listening to German). If English speakers with enough proficiency in and exposure to German (or another language which benefits significantly from suprasegmental stress cues) then they may also show more success in attending to stress information.

\section{Conclusion}

The present studies provide further evidence that the use of speech cues to stress is driven by vocabulary structure; listeners use stress distinctions to the degree that it facilitates word recognition in their language. This leads to even closely related languages such as German and English showing mismatches in the processing of suprasegmental cues.

\section{Acknowledgements}

Thanks to Isabell Wartenburger, Sandra Hanne, Carola De Beer, and Clara Huttenlauch for feedback and hospitality at Potsdam University during the testing of German listeners for Experiment 1 and 2. This project was funded by ARC Centre of Excellence for the Dynamics of Language (project ID: CE140100041) and by the Deutsche Forschungsgemeinschaft (DFG, German Research Foundation) - Project number 317633480 - SFB 1287, Project B01.

\section{Appendix}

1. Test pairs used in the German experiment. In each pair, the first member has primary stress on the first syllable.

Abschied, abstrakt; Aktie, Aktion; Arche, Archiv; Atlas, Athlet; Bruder, brutal; chemisch, Chemie; Chronik, Chronist; Dose, Dozent; Globus, global; Hupe, human; Kompass, kompakt; Konto, Konzept; Logik, lokal; Marke, markant; Masse, massiv; Moped, mobil; Motor, Motiv; Profi, Profit; Segel, Sequenz; tote, total; Tresen, Tresor; Turban, Turbine; Turner, Turnier.

2. Test pairs used in the English experiment. In each pair, the first member has primary stress on the first syllable.

campus, campaign; carton, cartoon; cashew, cashier; convent, convex; distance, distinct; district, distress; diver, divert; harpist, harpoon; humid, humane; impact, impress; influence, inform; liquid, liqueur; massive, masseur; motive, motel; music, museum; mystic, mistake; robot, robust; ruler, roulette; typhus, typhoon; union, unique. 


\section{References}

[1] M. Gordon and T. Roettger, "Acoustic correlates of word stress: A cross-linguistic survey," Linguistic Vanguard, vol. 3, 2017.

[2] P. Roach, English Phonetics and Phonology, 4th Ed. Cambridge: Cambridge University Press, 2009.

[3] A. Cutler and A. Jesse. Word stress in speech perception. In L. C. Nygaard, J. S. Pardo, D. B. Pisoni, and R. E. Remez. The Handbook of Speech Perception, 2nd Ed. New York: WileyBlackwell, in press.

[4] N. Cooper, A. Cutler, and R. Wales, "Constraints of lexical stress on lexical access in English: Evidence from native and non-native listeners," Language and Speech, vol. 45, no. 3, pp. 207-228, 2002.

[5] A. Cutler, "Forbear is a homophone: Lexical prosody does not constrain lexical access," Language and Speech, vol. 29, pp. 201-220, 1986.

[6] B. D. Fear, A. Cutler, and S. Butterfield., "The strong/weak syllable distinction in English," Journal of the Acoustical Society of America, vol. 97, pp. 1893-1904, 1995.

[7] L. M. Slowiaczek, "Effects of lexical stress in auditory word recognition," Language and Speech, vol. 33, pp. 47-68, 1990.

[8] A. Cutler and W. van Donselaar, "Voornaam is not (really) a homophone: Lexical prosody and lexical access in Dutch," Language and Speech, vol 44, pp. 171-195, 2001.

[9] W. van Donselaar, M. Koster, and A. Cutler, "Exploring the role of lexical stress in lexical recognition," Quarterly Journal of Experimental Psychology, vol. 58A, pp. 251-273, 2005.

[10] W. Jongenburger, and V. van Heuven, "The role of lexical stress in the recognition of spoken words: Prelexical or postlexical?" Proceedings of Thirteenth ICPhS, Stockholm, pp. 368-371, 1995.

[11] V. van Heuven, and M. de Jonge, "Spectral and temporal reduction as stress cues in Dutch", Phonetica, vol. 68, pp. 120-132, 2012.

[12] A. Cutler, and D. Pasveer, "Explaining cross-linguistic differences in effects of lexical stress on spoken-word recognition," in Proceedings of Speech Prosody 2006, Dresden, Germany, pp. 237-240, 2006.

[13] A. Cutler, D. Norris, and N. Sebastián-Gallés, "Phonemic repertoire and similarity within the vocabulary" in Proceedings of INTERSPEECH 2004 - $8^{\text {th }}$ Conference on Spoken Language Processing, Seoul, South Korea, pp. 65-68, 2004.

[14] T. Becker. Einführung in die Phonetik und die Phonologie des Deutschen. Darmstadt: Wissenschaftliche Buchgesellschaft, 2012.

[15] C. K. Friedrich, S. A. Kotz, A. D. Friederici, and K. Alter, "Pitch modulates lexical identification in spoken word recognition: ERP and behavioral evidence," Cognitive Brain Research, vol. 20, pp. 300-308, 2004.

[16] C. K. Friedrich, S. A. Kotz, A. D. Friederici, and T. C. Gunter, "ERPs reflect lexical identification in word fragment priming," Journal of Cognitive Neuroscience, vol. 16, pp. 541-552, 2004.

[17] U. Schild, A. B. Becker, and C. K. Friedrich. "Phoneme-free prosodic representations are involved in pre-lexical and lexical neurobiological mechanisms underlying spoken word processing," Brain and Language, vol. 136, pp. 31-43 (2014).

[18] A. Cutler, T. Otake, and L. Bruggeman, "Phonologically determined asymmetries in vocabulary structure across languages," Journal of the Acoustical Society of America, vol. 132, pp. EL155-EL160, 2012.

[19] R. H. Baayen, R. Piepenbrock, and L. Gulikers. CELEX2 LDC96L14. Web Download. Philadelphia: Linguistic Data Consortium, 1995.

[20] P. Boersma and D. Weenink. Praat: doing phonetics by computer. Version 6.0.50. http://www.praat.org/, 2019.

[21] N. S. Presentation, ed. Berkeley, CA, 2000.
[22] R Development Core Team, R., "R: A language and environment for statistical computing," Vienna: R Foundation for Statistical Computing, 2015.

[23] R. H. Baayen, D. J. Davidson, and D. M. Bates, "Mixed-effects modeling with crossed random effects for subjects and items," Journal of Memory and Language, vol. 59, pp. 390-412, 2008.

[24] H. Matuschek, R. Kliegl, S. Vasishth, H. R. Baayen, and D. M. Bates, "Balancing type 1 error and power in linear mixed models," Journal of Memory and Language, vol. 94, pp. 305315, 2017.

[25] S. Soto-Faraco, N. Sebastián-Gallés, and A. Cutler, "Segmental and suprasegmental mismatch in lexical access," Journal of Memory and Language, vol. 45, pp. 412-432, 2001.

[26] K. Lemhöfer and M. Broersma, "Introducing LexTALE: A quick and valid Lexical Test for Advanced Learners of English," Behavior Research Methods, vol 44, pp. 325-343, 2012.

[27] R. Lenth, "emmeans: Estimated Marginal Means, aka LeastSquares Means, R package version 1.2.3. https://CRAN.Rproject.org/package=emmeans," 2018.

[28] EF English Proficiency Index ( $8^{\text {th }}$ Edition), EF Education First Ltd, 2018

[29] A. Tremblay, "Proficiency assessment standards in second language acquisition research: "Clozing" the gap," Studies in Second Language Acquisition, Vol. 33, pp. 339-372, 2011.

[30] A Tremblay, "Phonetic variability and the variable perception of L2 word stress by French Canadian listeners," International Journal of Bilingualism, Vol. 13, pp. 35-62.

[31] A. Tremblay, M. Broersma, C.E. Coughlin, and J. Choi, "Effects of the native language on the learning of fundamental frequency in second-language speech segmentation," Frontiers in Psychology, Vol. 7, no. 985 .

[32] J.L. McDonald, "Beyond the critical period: Processing-based explanations for poor grammaticality judgment performance by late second language learners," Journal of Memory and Language, Vol. 55, pp. 381-401, 2006.

[33] A Weber, and M, Broersma, "Spoken word recognition in second language acquisition," The Encyclopedia of Applied Linguistics, pp. 5368-5375, 2012. 